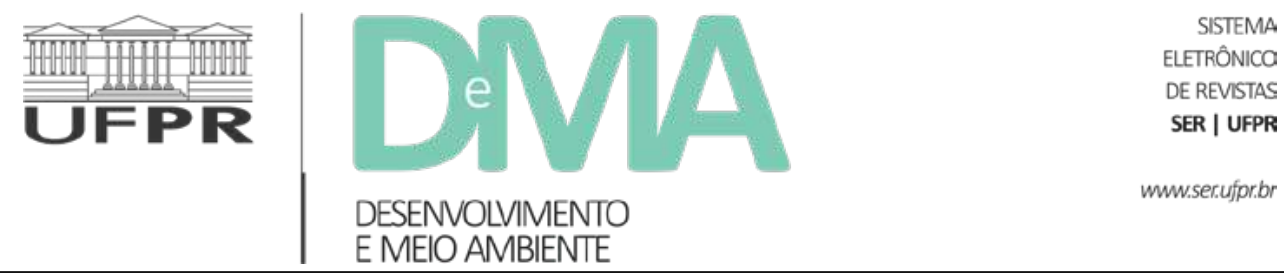

\title{
Marco normativo das Reservas Extrativistas brasileiras: a construção social de uma tutela jurídica ambiental
}

\section{Normative framework of Brazilian Extractive Reserves: a social construction of an environmental legal protection}

\author{
Manoel Eduardo Alves Camargo e GOMES ${ }^{1}$, Adriano Camargo GOMES ${ }^{2 *}$ \\ ${ }^{1}$ Universidade Federal do Paraná (UFPR), Curitiba, PR, Brasil. \\ ${ }^{2}$ Universidade Positivo (UP), Curitiba, PR, Brasil. \\ *E-mail de contato: adriano@camargoegomes.com
}

Artigo recebido em 23 de abril de 2018, versão final aceita em 9 de outubro de 2018.

RESUMO: $\quad$ Este artigo analisa o marco legal das Reservas Extrativistas brasileiras. O seu objetivo é apresentar um panorama das principais normas jurídicas relativas a essa unidade de conservação - unidade que se distingue das demais previstas no Sistema Nacional de Unidades de Conservação da Natureza (SNUC). O estudo adota uma perspectiva cronológica, de 1987, quando foi editada a portaria que criou a modelagem de Projeto de Assentamento Extrativista (PAE), até 2018, quando foi editada a Portaria Conjunta $\mathrm{n}^{\circ}$ 96/2018, que institui a Comissão das Reservas Extrativistas Federais (CONAREX), órgão responsável pela elaboração da minuta de um novo decreto de regulamentação das Reservas Extrativistas. Ao longo do texto pretende-se demonstrar a insuficiência do atual marco legal e a necessidade de uma nova regulação para proteger mais efetivamente os meios de vida e a cultura da população extrativista tradicional.

Palavras-chave: direito ambiental; Reservas Extrativistas; Sistema Nacional de Unidades de Conservação da Natureza; SNUC; marco legal das Reservas Extrativistas; políticas públicas; participação popular.

ABSTRACT: This article analyzes the legal framework of the Brazilian Extractive Reserves. Its purpose is to present a picture of the main legal rules provided for the regulation of the Extractive Reserves, which are consistently different from those provided for other conservation units in the Brazilian National System of Nature Conservation Units (SNUC). This study adopts a chronological perspective, starting from 1987, when the regulation that created the model of the extractive settlement project was edited, to 2018, when the Ordinance No. 96/2018 was edited to establish the Extractive Reserves Committee (CONAREX), an organ which is in charge of drafting a new regulation on Extractive Reserves. This article sought to demonstrate the insufficiency of the 
current legal framework and the necessity of a new regulation to protect more effectively the means of life and the culture of the traditional extractive people.

Keywords: environmental law; Extractive Reserves, Brazilian National System of Nature Conservation Units; SNUC, legal framework of Brazilian Extractive Reserves; public policies; public participation.

\section{Introdução}

Em julho de 1989, com a edição da Lei $\mathrm{n}^{\circ}$ 7.804/1989, o Brasil institucionalizou as Reservas Extrativistas como um dos instrumentos da Política Nacional de Meio Ambiente. Como consequência, coube ao Estado o dever de considerar o extrativismo tradicional como objeto de tutela jurídica ambiental.

Esse novo papel do Poder Público em relação às Reservas Extrativistas foi fruto de um longo e contínuo processo de lutas e conquistas que aglutinou diversos segmentos como lideranças populares, intelectuais reunidos em torno de organizações não-governamentais e agentes públicos voltados à causa ambiental. Como assinalado em $1989^{1}$, os esforços dos movimentos ambientalistas constituem ação histórica imprescindível na constituição de novas tutelas públicas ao meio ambiente. Esses esforços, levados a efeito por lideranças sociais como Chico Mendes, foram determinantes no processo de institucionalização das Reservas Extrativistas, culminando na previsão e disciplinamento legal do extrativismo sustentável.

De fato, do final do século XIX - quando milhares de nordestinos migraram para a Região Amazônica - até os dias atuais - quando o extrativismo sustentável encontra previsão e disciplinamento legal - ocorreram inúmeros fatos, tanto no plano político quanto no plano jurídico, que, articulados entre si, acabaram por determinar a institucionalização das Reservas Extrativistas.

O discurso de Chico Mendes para comemorar a criação oficial do Projeto de Assentamento Extrativista, na comunidade de Cachoeira, em Xapuri (AC) deixa clara a gravidade desses acontecimentos:

\begin{abstract}
Tenho o compromisso de continuar essa luta, marcada com o sacrifício, sangue e até cadáver dos nossos companheiros. Apesar de saber que vai haver mais assassinatos, pois a UDR não está contente com esta nossa primeira vitória, não temos medo. Eles podem matar um, dois, três ou dez, mas não conseguirão acabar com a organização e resistência, que darão mais vitórias aos seringueiros. Temos consciência que será às custas de muito sangue que mais Reservas Extrativistas ${ }^{2}$ serão implantadas. A UDR não conseguirá nos desmobilizar com a violência, temos consciência da existência de uma entidade assassina entre nós. Não é porque um morre que vamos desanimar. ${ }^{3}$
\end{abstract}

O conjunto de acontecimentos políticos e sociais que determinaram a constituição das Reservas Extrativistas como unidade de conservação não serão aqui analisados. Este trabalho terá como objeto apenas os três principais diplomas normativos existentes no direito brasileiro que, diretamente,

\footnotetext{
${ }^{1}$ Gomes, M. E. A. C. e. Participação popular no controle ambiental. Revista de Informação Legislativa. Brasília, a. 26, n. 104, out./dez. 1989 . p. 336.

${ }^{2}$ Leia-se: Projeto de Assentamento Extrativista.

${ }^{3}$ Allegretti, M. H. A Construção Social de Políticas Ambientais: Chico Mendes e o movimento dos seringueiros. Tese de Doutorado. Brasília, Universidade de Brasília, 2002, p. 348.
} 
recepcionam o extrativismo tradicional sustentável como objeto da tutela do Estado.

Entre os diversos critérios metodológicos disponíveis, o mais didático parece ser o cronológico, na medida em que observa o processo sociopolítico subjacente à "juridicização" do extrativismo tradicional sustentável. Não obstante a adoção desse critério para o estabelecimento da ordem de exposição, a análise terá uma perspectiva fundamentalmente sincrônica, com o singelo objetivo de situar o leitor no campo dos três principais marcos normativos do extrativismo sustentável no Brasil: a Portaria ${ }^{\circ}$ 627/1987, editada pelo Instituto Nacional de Colonização e Reforma Agrária (INCRA), o Decreto ${ }^{\circ}$ 98.897/1990 e a Lei no $9.985 / 2000$.

Será também tratada, de modo muito superficial, a instituição recente de dois espaços estatais que contemplam participação da população extrativista: a Comissão das Reservas Extrativistas Federais-CONAREX, instituída pela Portaria Conjunta ICMBio/MMA n ${ }^{\circ}$ 96/2018; e o Comitê Gestor do Plano Nacional de Fortalecimento das Comunidades Extrativistas e Ribeirinhas - PLANAFE, criado por força do Decreto ${ }^{\circ}$ 9.334/2018.

\section{O extrativismo sustentável como instrumento da Política Nacional da Reforma Agrária - PNRA}

O primeiro marco legal a tratar do extrativismo no Brasil foi a Portaria INCRA n ${ }^{\circ} 627 / 1987$. Con- cebendo o extrativismo como uma alternativa aos projetos fundiários executados pelo órgão gestor de terras da União, essa Portaria instituiu a modalidade de Projeto de Assentamento Extrativista (PAE).

Apesar de ser um ato administrativo ordinário, restrito ao âmbito interno do próprio órgão e sem força para atingir outras relações jurídicas ${ }^{4}$, a Portaria INCRA n ${ }^{\circ} 627 / 1987$ contemplou duas inovações: i) a adoção do instrumento contratual da concessão de uso; e ii) a possibilidade de utilização "associativista, condominial ou cooperativista" da área 5 .

A opção pelo instrumento da concessão de uso possibilitou a concepção de um modelo de assentamento que permite, a um só tempo, a destinação individualizada (uti singuli) da área e a imposição de condições especiais ao concessionário, entre as quais a impossibilidade de transferência dos direitos do contrato para terceiros (intransmissibilidade inter vivos). ${ }^{6}$

A possibilidade de utilização "associativista, condominial ou cooperativista", por sua vez, avançou em relação ao modelo então tradicional de parcelamento do solo em lotes, que era incompatível com a atividade extrativista. Afinal, essa atividade costuma ser caracterizada por percursos que se sobrepõem, por exemplo, nas "estradas de seringa" utilizadas para a extração de látex.

Em que pese esse arranjo tenha se constituído em um avanço, aperfeiçoamentos seriam necessários para alcançar a desejada suficiência. Viana e Sales - ao parafrasear Rueda, Gomes e Felippe, e Allegretti - apontam:

\footnotetext{
${ }^{4}$ Gomes, M. E. A. C.; Felippe, L. D. Tutela jurídica sobre as reservas extrativistas. In: Arnt, R. (ed.). O destino da floresta: reservas extrativistas e desenvolvimento sustentável na Amazônia. Rio de Janeiro/Curitiba: Relume-Dumará \& Instituto de Estudos Amazônicos e Ambientais, 1994. ${ }^{5}$ Essas inovações foram estabelecidas no inciso II da Portaria 627/1987 nos seguintes termos: "Estabelecer que a destinação das áreas para tais projetos dar-se-á mediante concessão de uso, em regime comunial, segundo a forma decidida pelas comunidades concessionárias - associativista, condominial ou cooperativista."
} 
Apesar da Portaria $n^{\circ} 627$ atender as reivindicações do Encontro Nacional dos Seringueiros e apesar de dez assentamentos terem sido criados pelo Incra, alguns pontos ainda se mostravam frágeis na consolidação destas áreas enquanto pólos de desenvolvimento e de conservação ambiental: 1) o poder público se mostrou negligente em apoiar a implementação dos assentamentos, sendo que apenas três deles, no Acre, receberam algum suporte técnico e financeiro (Rueda, 1995); 2) a Portaria do Incra, em razão do próprio processo que a originou, referia-se apenas a áreas de seringais, inibindo a criação de novos assentamentos nos quais as populações se dedicassem ao extrativismo de outros recursos naturais, inclusive em outros ecossistemas que não os florestais; 3 ) o instrumento jurídico que criava os assentamentos era uma portaria, "mero ato administrativo ordinatório e, como tal, adstrito ao âmbito interno do próprio órgão que a expediu, sem força para sujeitar qualquer relação jurídica exterior" (Gomes \& Felippe, 1994) e 4) a política de reforma agrária perdeu força em meados da década de oitenta e as desapropriações para criação dos assentamentos extrativistas tornaram-se mais difíceis (Allegretti, 1994). ${ }^{7}$

Diante dessas fragilidades, o movimento protagonizado pelo então Conselho Nacional dos Seringueiros $(\mathrm{CNS})^{8}$ continuou a pressionar fortemente $\mathrm{o}$ governo para que o conceito de Reserva Extrativista, como unidade de conservação ambiental, fosse também recepcionado no âmbito da política e dos órgãos do meio ambiente. ${ }^{9}$

\section{Reserva Extrativista como instrumento da Política Nacional do Meio Ambiente}

A Constituição Federal, promulgada em outubro de 1988, com um capítulo dedicado ao meio ambiente, acabou por determinar um espaço muito específico para a inserção do extrativismo sustentável na legislação ordinária brasileira.

As inovações trazidas pela constitucionalização do meio ambiente determinaram um extraordinário plexo de transformações na legislação infraconstitucional atinente à matéria, inclusive na própria Lei $n^{\circ} 6.938 / 1981$, concebida para estruturar a Política Nacional do Meio Ambiente, nutrida, então, por fortes movimentos nacionais e internacionais de defesa ambiental.

A Lei $n^{\circ} 7.804 / 1989$, alterando a Lei ${ }^{\circ}$ 6.938/1981, compatibilizou a Política Nacional do Meio Ambiente com as disposições constitucionais, ${ }^{10}$ incluindo as Reservas Extrativistas em seu rol de instrumentos:

Art. $9^{\circ}$. São instrumentos da política nacional de meio ambiente:

$[\ldots]$

\footnotetext{
${ }^{6} \mathrm{Na}$ elaboração do Decreto $\mathrm{n}^{\circ}$ 98.897/1990, outras vantagens apresentadas por esse instrumento foram consideradas, como: a) a possibilidade de manter a dominialidade pública do território; b) concedendo-se o uso coletivo da área; c) destinando-o para uma pessoa jurídica, constituída na forma de associação; d) com regramento que condiciona o direito de uso ao uso sustentável dos recursos naturais. Mary Allegretti assim se pronuncia a respeito: "O conceito de concessão real de uso está na legislação que trata do direito de uso de propriedades públicas (Decreto-Lei N. 271, de 27/02/1967). Ao realizar a concessão para a comunidade e não para os individuos, assegura valores e responsabilidade partilhadas por todos e a garantia de que os recursos naturais serão extraídos de forma sustentável. A proposição deste modelo para os seringueiros e sua formulação nos termos do Decreto 98.987 de 30.01.1990 foi uma contribuição do advogado Manoel Eduardo Camargo e Gomes ao CNS e ao IEA" [Allegretti, M. H. A Construção Social de Políticas Ambientais: Chico Mendes e o Movimento dos Seringueiros. Tese de Doutorado. Brasília, Universidade Brasília, 2002, p. 25].

${ }^{7}$ Vianna, L. P.; Sales, R. R. de. Análises e diretrizes para consolidação da categoria reserva extrativista. Brasília: WWF-Brasil, 2008.

${ }^{8}$ Em 2009, o Conselho Nacional dos Seringueiros assou a ser denominado "Conselho Nacional das Populações Extrativistas", mantendo a mesma sigla "CNS".

${ }^{9}$ Por uma etnografia detalhada desse movimento, ver Allegretti, M. H. A Construção Social de Políticas Ambientais: Chico Mendes e o Movimento dos Seringueiros. Tese de Doutorado. Brasília, Universidade Brasília, 2002.
} 
VI) a criação de espaços territoriais especialmente protegidos pelo Poder Público Federal, Estadual e Municipal, de relevante interesse ecológico e Reservas Extrativistas.

Com esse dispositivo, as Reservas Extrativistas foram abrigadas no seu habitat natural, a política nacional de meio ambiente. Além disso, pela expressa menção às Reservas Extrativistas, abria-se a possibilidade de que a matéria recebesse disciplina normativa por meio de decreto, conferindo-lhe o status de instituto juridicamente tutelado pelo Poder Público.

\section{Regulamentação das Reservas Extrativistas: Decreto n ${ }^{\circ}$ 98.897/1990}

Em razão da natureza principiológica do art. $9^{\circ}$, VI, Lei $n^{\circ} 6.938 / 1981$, com redação dada pela Lei $n^{0} 7.804 / 1989$, tornava-se imperioso o órgão gestor da Política Nacional de Meio Ambiente regulamentar as Reservas Extrativistas, até então desconhecidas no direito brasileiro e na própria tecnoburocracia estatal.

Em setembro de 1989, com o acirramento da pressão do movimento social, impactado com o assassinato do líder extrativista Chico Mendes em dezembro de 1988 e com a fragilidade do diálogo mantido pelo governo brasileiro com a comunidade internacional, somada à necessidade de regulamentação da Lei no ${ }^{0}$.804/1989, a Presidência do IBAMA criou um Grupo de Trabalho composto por um engenheiro agrônomo do INCRA, um engenheiro agrônomo do próprio IBAMA, um advogado indicado pelo Instituto de Estudos Amazônicos (IEA) e duas lideranças do Conselho Nacional dos Serin- gueiros (CNS). O propósito do Grupo de Trabalho era regulamentar o art. $9^{\circ}$, VI, Lei $n^{\circ} 6.938 / 1981$, em decorrência de sua nova redação.

$\mathrm{Na}$ condição de advogado representante do IEA, Manoel Eduardo Alves Camargo e Gomes, um dos autores deste artigo, obteve a concordância do então presidente do IBAMA para que, em vez de regulamentar o dispositivo referente às Reservas Extrativistas no âmbito do extenso decreto que viria a regulamentar toda a Lei $\mathrm{n}^{\circ} 7.804 / 1989$, fosse editado um decreto específico sobre as Reservas Extrativistas.

Essa estratégia de deslocamento da regulamentação para um decreto específico tornou possível ao Grupo de Trabalho ampliar sua competência - de elaborar apenas um artigo estabelecendo os termos pelos quais as Reservas Extrativistas deveriam ser utilizadas como instrumento da Política Nacional do Meio Ambiente - para elaborar um documento que, ao institucionalizar as Reservas Extrativistas como Unidade de Conservação, oferecesse os elementos necessários para a imediata criação de áreas capazes de proteger o extrativismo sustentável e a população tradicional.

Surgia o Decreto n ${ }^{\circ} 98.897 / 1990$, assinado em 30 de janeiro de 1990: a Presidência do IBAMA apresentou ao Presidente da República, sem qualquer alteração, a minuta elaborada pelo referido advogado e aprovada pelo Grupo de Trabalho depois de ampla discussão em Rio Branco, no Acre, junto com as principais lideranças do movimento extrativista.

Na mesma ocasião, por pressão da população extrativista tradicional, organizada em torno do CNS, de técnicos, intelectuais e artistas envolvi-

\footnotetext{
${ }^{10}$ Notadamente, o art. 225, $\S 1^{\circ}$, III, CF/88, que conferiu ao Poder Público o dever de "definir, em todas as unidades da Federação, espaços territoriais e seus componentes a serem especialmente protegidos".
} 
dos com a causa ambiental, foram criadas quatro reservas: 1) Reserva Extrativista Chico Mendes (AC), com 970.570 ha (Decreto no 99.144/1990); 2) Reserva Extrativista Rio Ouro Preto (RO), com 204.583 ha (Decreto ${ }^{\circ}$ 99.146/1990); 3) Reserva Extrativista Rio Cajari (AP), com 481.650 ha (Decreto no 99.145/1990); 4) Reserva Extrativista do Alto Juruá (AC), com 506.186 ha (Decreto ${ }^{\circ}$ $98.863 / 1990$, publicado seis dias antes do próprio Decreto $\left.n^{\circ} 98.897 / 1990\right)^{11}$.

As ideias básicas que nortearam a redação do Decreto ${ }^{\circ} 98.897 / 1990$, foram 1) a dominialidade pública; 2) o uso coletivo da área; 3) a administração e gestão da área por uma associação formada por membros da comunidade; 4) a delegação por meio de contrato de concessão de direito real de uso; 5) a outorga, pela associação concessionária, de autorizações de uso aos moradores que tradicionalmente residiam no perímetro da unidade. ${ }^{12}$

O Decreto ${ }^{\circ} 98.897 / 1990$ fixa, em seu art. $1^{\circ}$, o conceito de Reserva Extrativista nos seguintes termos:

Art. $1^{\circ}$. As Reservas Extrativistas são espaços territoriais destinados à exploração auto-sustentável e conservação dos recursos naturais renováveis, por populações extrativistas.

Esse conceito se destaca por possuir considerável referibilidade à base empírica que o informa, reduzindo as deformações habitualmente presentes entre a realidade social e a construção jurídico-positiva. Essa referibilidade é expressa por dois termos-conceitos: "conservação de recursos naturais" e "exploração autossustentável". Com eles, conjuga-se o binômio conservação/exploração, indica-se o bem jurídico tutelado, o modus faciendi da exploração e os destinatários da unidade e responsáveis pela exploração: a população extrativista.

Essa formulação conceitual híbrida, composta por dois núcleos semânticos até então polarizados (exploração/conservação), é paradigmática em relação ao intento constituinte deduzido no art. 225, $\S 4^{\circ}, \mathrm{CF} / 88$, que, considerando a Floresta Amazônica brasileira, a Mata Atlântica, a Serra do Mar, o Pantanal Mato-Grossense e a Zona Costeira como Patrimônio Nacional, condiciona sua utilização "às condições que assegurem a preservação do meio ambiente, inclusive quanto ao uso dos recursos naturais".

Cuida-se, portanto, de um importante acréscimo, não previsto no art. $225, \S 1^{\circ}$, III, $\mathrm{CF} / 88$, e que possui incidência sobre todo o território nacional. Com ele, o direito brasileiro passou a reconhecer a possibilidade de que a exploração de recursos naturais renováveis - quando autossustentável e realizada por populações extrativistas tradicionais - é servível para a conservação desses mesmos recursos.

Esse acréscimo corresponde ao estabelecimento de um dever tutelar do Estado, considerando a existência de interesse ecológico e social, tal como dispõe o art. $2^{\circ}$, Decreto ${ }^{\circ} 98.897 / 1990$ :
Art. $2^{\circ}$. O Poder Executivo criará Reservas Extrativistas em espaços considerados de interesse ecológico e social. Parágrafo único. São espaços territoriais considerados de interesse ecológico e social as áreas que possuam características naturais ou exemplares da biota que pos- sibilitem a sua exploração auto-sustentável, sem prejuízo da conservação ambiental.

\footnotetext{
${ }^{11}$ Esses decretos, nos termos do art. 225, $\S 1^{\circ}$, III, CF/88, somente podem ser revogados ou derrogados por lei, e, mesmo nesse caso, sem que se comprometa a vocação extrativista autossustentável da região.

${ }^{12}$ Ver nota de rodapé 4.
} 
A qualificação do fundamento desse dever tutelar, expresso na construção de um novo termo-conceito (interesse ecológico e social), estabelece a finalidade do ato instituidor da Reserva Extrativista, com todos os seus consectários jurídico-doutrinários - inclusive o controle jurisdicional a partir do desvio do poder, entendido como "o desencontro entre a finalidade do ato e a finalidade legal que o condiciona". ${ }^{13}$ A previsão desse termo-conceito como elemento de fundamentação do ato (finalidade) tem repercussões não apenas na destinação mas também na utilização da área. Não se deve deduzir - como se poderia supor a partir de uma interpretação literal da parte final do artigo - que a população extrativista tradicional é agraciada com a área da Reserva Extrativista. Em verdade, pela concessão da área, referida população não é destinatária de um especial benefício, mas de um múnus público: uma obrigação imposta por lei em prol do interesse público na proteção do meio ambiente. Essa obrigação decorre do background e do modus vivendi da população extrativista tradicional que a capacita para cumprir a finalidade indicada na lei: explorar a área de maneira autossustentável, sem prejuízo da conservação ambiental. Esses aspectos constituem o supedâneo jurídico da dispensa de concorrência pública prévia, então prevista no art. $15, \S 1^{\circ}$, Decreto-Lei ${ }^{\circ} 2.300 / 1986^{14}$, exigível em todos os contratos firmados pelo Poder Público.

Note-se, ainda, que não é só a validade do ato de criação dessas unidades que se condiciona ao atendimento desse escopo legal, mas também a sua própria manutenção. Isso quer dizer que a área destinada ao extrativismo sustentável só manterá o status de Reserva Extrativista e, como tal, será tutelada pelo Estado, quando criada e mantida nos contornos do interesse ecológico e social.

Desse modo, também fica reforçada a legitimidade de ampla fiscalização do órgão gestor do meio ambiente sobre as Reservas Extrativistas, justificada agora não apenas pela sua titularidade dominial sobre a área, mas também pela finalidade para a qual foi instituída como Unidade de Conservação.

Assim, qualquer dano causado por ação ou omissão, atribuível aos órgãos públicos ou à população extrativista concessionária da área, é passível de responsabilização objetiva, nos exatos termos do art. $37, \S 6^{\circ}, \mathrm{CF} / 88^{15}$, sem prejuízo do disposto no art. $225, \S 3^{\circ}, \mathrm{CF} / 88^{16}$, que, inclusive, criminaliza os atos e omissões de pessoas jurídicas.

Nesse sentido, o art. $5^{\circ}$, Decreto ${ }^{\circ} 98.897 / 1990$, dispõe sobre o controle ou fiscalização das Reservas Extrativistas:

Art. $5^{\circ}$. Caberá ao 1BAMA supervisionar as áreas extrativistas e acompanhar o cumprimento das condições estipuladas no contrato de que trata o artigo anterior.

Como leciona Bandeira de Mello, "cada plexo de poderes é instituído para alvejar determinado escopo; onde, cada ato exercido em nome de tal competência tem, ipso facto, um endereço certo, predeterminado: o correspondente à competência do qual é expressão concreta" ${ }^{17}$. Assim, a autoridade

\footnotetext{
${ }^{13}$ Mello, C. A. B. de. "Legalidade - discricionariedade - seus limites e controle". Revista de Direito Público, são Paulo, Ed. Revista dos Tribunais, (86): 42-59, abr./Jun. 1988, p. 46.

${ }^{14}$ Referido Decreto-Lei foi revogado pela Lei ${ }^{\circ}$ 8.666/1993, que disciplina o tema atualmente.

${ }^{15}$ Art. 37, $\S 6^{\circ}, \mathrm{CF} / 88$ : “As pessoas jurídicas de direito público e as de direito privado prestadoras de serviços públicos responderão pelos danos que seus agentes, nessa qualidade, causarem a terceiros, assegurado o direito de regresso contra o responsável nos casos de dolo ou culpa".

${ }^{16}$ Art. $225, \S 3^{\circ}, \mathrm{CF} / 88$ : “As condutas e atividades consideradas lesivas ao melo ambiente sujeitarão os infratores, pessoas físicas ou jurídicas a sanções penais e administrativas, independentemente da obrigação de reparar os danos causados”.
} 
pública concedente - em atuação discricionária ou vinculada - estará sempre adstrita ao dever de atender à finalidade legal, fazendo-a se subsumir à realidade social da forma mais precisa possível, sob pena de responder pelo eventual desvio.

Os requisitos para o ato de criação de Reservas Extrativistas foram estabelecidos pelo art. $3^{\circ}$, Decreto $n^{\circ}$ 98.897/1990:

Art. 3. ${ }^{\circ}$ - Do ato de criação constarão os limites geográficos, a população destinatária e as medidas a serem tomadas pelo Poder Executivo para a sua implantação, ficando a cargo do Instituto Brasileiro do Meio Ambiente e dos Recursos Naturais Renováveis - IBAMA, as desapropriações que se fizerem necessárias.

Em verdade, esse artigo dispõe sobre dois elementos: o primeiro deles, o ato de criação da Reserva Extrativista, que, conforme o decreto, deve estabelecer "os limites geográficos, a população destinatária e as medidas a serem tomadas pelo Poder Executivo"; o segundo, a competência para proceder às desapropriações, que é retirada do INCRA e transferida ao IBAMA - entidade então responsável pelas unidades de conservação federais. Este elemento, apesar de ser de natureza meramente procedimental, teve profundos reflexos políticos e orçamentários, já que transferiu ao próprio órgão gestor do meio ambiente a competência para proceder às desapropriações.

Quanto ao primeiro elemento, não se notam os mesmos reflexos: ao se exigir, no ato da criação, a publicidade dos limites geográficos, da população destinatária e das medidas a serem tomadas pelo Poder Público para sua implantação, esses dados são integrados no contexto da motivação do ato, permitindo seu controle. Assim, ainda que superficialmente, convém analisar os contornos conceituais dos três requisitos previstos para o ato de criação.

A expressão limites geográficos significa a definição do polígono da área e não a caracterização fundiária (levantamento cadastral, levantamentos de títulos e registros, diagnósticos da área, levantamento de ocupações, etc.) eventualmente necessária para a desapropriação. Desse modo, caberá ao Poder Público, por meio de seus órgãos técnicos, estabelecer tão-somente o perímetro com suas características certas ou aproximadas.

É também condição para a criação das Reservas Extrativistas a identificação da população destinatária e, nesse sentido, o próprio legislador estabelece o perfil da população capaz de fazer frente a este múnus público: a extrativista tradicional. $\mathrm{O}$ que se quer é contemplar comunidades extrativistas tradicionais que, ao longo dos anos, criaram valioso e insubstituível arcabouço sociocultural voltado à exploração ecologicamente sustentável dos recursos naturais renováveis, extraindo deles seu sustento.

As medidas a serem tomadas pelo Poder Executivo consistem, num primeiro momento, na identificação da área (necessária também para permitir uma segura decisão sobre a conveniência e viabilidade de criação das Reservas Extrativistas); num segundo momento, na regularização fundiária (providência que permite a concentração da área no domínio público, viabilizando, assim, a exploração condominial através dos contratos de concessão de direito real de uso) ${ }^{18}$; e, num terceiro momento, na fiscalização e fornecimento de infraestrutura que viabilize a adequada gestão da Reserva Extrativista.

\footnotetext{
${ }^{17}$ Mello, C. A. B. de. Legalidade - discricionariedade: seus limites e controle'. Revista de Direito Público, são Paulo, Ed. Revista dos Tribunais, v. 86 , abr/jun. 1988 , p. $42-59$, p. 46.
} 
Em 1994, após a criação do Centro Nacional de Desenvolvimento Sustentado das Populações Tradicionais - $\mathrm{CNPT}^{19}$, foi estabelecido, também por Portaria ${ }^{20}$, um roteiro para criação e implantação de Reservas Extrativistas que prevê 12 fases: solicitação dos moradores; instituição da associação dos moradores; vistoria do Poder Público; complementação de dados para a criação; aprovação da área para criação; regularização fundiária e imissão de posse; cadastramento dos moradores; plano de utilização; carta de anuência dos moradores ao plano; aprovação do plano; celebração do contrato de concessão de direito real de uso; e plano de desenvolvimento da Reserva.

O Decreto $n^{\circ}$ 98.897/1990 também prescreve as condições estruturais de funcionamento das Reservas Extrativistas:

Art. 4. ${ }^{\circ}$ - A exploração auto-sustentável e a conservação dos recursos naturais será regulada por contrato de concessão real de uso, na forma do art. $7 .^{\circ}$ do Decreto-Lei n. ${ }^{\circ} 271$, de 28 de fevereiro de 1967.

$\S 1 .^{\circ}$ - O direito real de uso será concedido a título gratuito.

$\S 2 .^{\circ}$ - O contrato de concessão incluirá o plano de utilização aprovado pelo IBAMA e conterá cláusula de rescisão quando houver quaisquer danos ao meio ambiente ou a transferência da concessão inter-vivos.

Agiram bem os proponentes do Decreto ao prever o contrato de concessão de direito real de uso como instrumento jurídico utilizado para regular a exploração e a conservação das Reservas Extrativis$\operatorname{tas}^{21}$. Trata-se de instrumento contratual por meio do qual a Administração transfere o uso, remunerado ou gratuito, de terreno público a particular, como direito real resolúvel, para que dele se utilize para fins de exploração que apresentem interesse social.

Acertou também ao fazer expressa menção ao Decreto-Lei ${ }^{\circ} 271 / 1967$, porque com isso evitou a confusão, muito corrente, entre a concessão de uso como direito real sobre coisa alheia e os institutos da concessão de uso administrativo e do direito real de uso previsto nos arts. 742 e ss, Código Civil então vigente.

Ressalte-se, ainda, a boa técnica legislativa ao mencionar expressamente o art. $7^{\circ}$, Decreto-Lei 271/1967, fazendo incidir impostergáveis preceitos normativos como: a) possibilidade de contratação por instrumento público ou particular, ou por simples termo administrativo $\left.\left(\S 1^{\circ}\right) ; b\right)$ a imediata fruição do terreno pelo concessionário, respondendo por todos os encargos legais sobre o imóvel e suas rendas $\left(\S 2^{\circ}\right)$; c) a rescindibilidade da concessão antes do seu termo, nos casos do concessionário dar destinação diversa ao imóvel ou descumprir cláusula resolutória, perdendo as benfeitorias de qualquer natureza, inclusive as úteis e necessárias $\left(\$ 3^{\circ}\right)$.

O contrato de concessão de direito real de uso oferece grande vantagem em relação a outras modalidades existentes no direito brasileiro, como, v.g., a alienação, a doação, a permissão, a autorização e

\footnotetext{
${ }^{18}$ Dependendo da natureza jurídica das titulações incidentes sobre a área, diferente será o procedimento a ser adotado para a regularização fundiária. Para tanto, as terras devolutas reclamam o devido processo discriminatório, enquanto as terras ou benfeitorias particulares devem ser incorporadas ao património público através do competente processo desapropriatório, função essa que era cometida ao IBAMA e, hoje, é de responsabilidade do ICMBio.

${ }^{19}$ Criado pela Portaria ${ }^{\circ} 22-\mathrm{N} / 92$ - IBAMA e regulamentado pela Portaria $\mathrm{n}^{\circ}$ 22-A/92 - IBAMA.

${ }^{20}$ Portaria IBAMA n ${ }^{\circ}$ 51-N/94, alterada por diversas outras Portarias (como. v.g., a Portaria IBAMA n ${ }^{\circ} 118 / 98$, a Portaria IBAMA n ${ }^{\circ} 02 / 98$ e a Portaria IBAMA n ${ }^{\circ}$ 76/99) que mantiveram não apenas a legitimidade da população de iniciar o processo de criação, como seu direito de, como concessionária, aprovar o plano de manejo, situação que só se alteraria com o advento da Lei nº 9.985/2000.

${ }^{21}$ Ver nota 06.
} 
o aforamento ou enfiteuse. ${ }^{22}$ Isso porque, por meio da concessão de direito real de uso, outorga-se ao particular apenas o direito de uso do bem público, mas garante-se sua oponibilidade erga omnes, vale dizer, a quem quer que seja, obrigando todos à sujeição ao direito de seu titular. ${ }^{23}$

A previsão de gratuidade contida no art. $4^{\circ}, \S$ $1^{\circ}$, Decreto $n^{\circ} 98.897 / 1990$, é consentânea com as peculiaridades que envolvem as populações extrativistas, despossuídas, em regra, de qualquer recurso.

$\mathrm{O}$ art. $4^{\mathrm{o}}, \S 2^{\circ}$, Decreto ${ }^{\circ} 98.897 / 1990$, prevê, também, a formalização do contrato mediante plano de utilização, instrumento previsto no art. $4^{\circ}, \S 2^{\circ}$, do Decreto $n^{\circ}$ 98.897/1990, o qual, como anexo ao contrato de concessão de direito real de uso, deve (a) ser aprovado pelo Poder Público, (b) conter clausula de rescisão quando houver quaisquer danos ao meio ambiente ou transferência da concessão inter vivos, além de normatizar o uso do espaço territorial e dos recursos naturais. ${ }^{24}$

O último requisito expresso no artigo citado diz respeito à intransmissibilidade dos direitos sobre a área. A concessão de direito real de uso, a exemplo dos demais direitos reais sobre coisas alheias, é transmissível, em regra, por ato inter vivos ou por sucessão legítima ou testamentária tal como dispõe o art. 7, $\S 4^{\circ}$, Decreto-Lei $n^{\circ} 271 / 67$. Contudo, no caso das Reservas Extrativistas, previu-se a intransmissibilidade como forma de impedir a transmissão por ato inter vivos. Trata-se de uma regra com alvo certo: vedar a especulação econômica a partir da concessão, forçando os membros da população extrativista tradicional a permanecerem na área, realizando sua exploração autossustentada.

\section{Inclusão das Reservas Extrativistas no Sistema Nacional de Unidades de Conservação: Lei $n^{\circ}$ 9.985/2000}

Durante os aproximadamente dez anos de vigência, sem nenhuma alteração, do Decreto $n^{\circ}$ 98.897/1990, “foram criadas 34 Reservas Extrativistas e três Reservas de Desenvolvimento Sustentáve ${ }^{25}$ na Amazônia, cobrindo uma área de mais de

\footnotetext{
${ }^{22}$ As duas primeiras transferem a titularidade do domínio, enquanto a concessão transfere apenas a titularidade do uso como direito real resolúvel. Os institutos da autorização e da permissão de uso, por definição legal, são sempre de natureza precária e unilateral e por essa razão não permitem um detalhamento dos direitos e obrigações das partes, tampouco oferecem segurança para quem os recebe. A concessão de uso, ao contrário, sendo um instrumento de natureza contratual, exige não só este detalhamento, como também fixa prazos e condições, o que confere maior segurança e estabilidade à relação jurídica. Prefere-se, ainda, o instituto da concessão ao do aforamento, porque esse já não alcança as exigências das relações contemporâneas. Como ensina Meirelles, "o aforamento é uma velharia que bem merecia desaparecer de nossa legislação e, principalmente, da prática administrativa que até hoje emperra a Administração local com obsoletas limitações ao domínio pleno dos bens municipais [...]" (Meirelles, H. L. Direito Administra tino Brasileiro, 17ª ed. São Paulo, Malheiros Editores, 1990, p. 442).

${ }^{23}$ A concessão de uso administrativa destina-se a outorgar ao particular a faculdade de utilizar um bem público, segundo sua peculiar destinação, afigurando-se como um contrato de natureza pessoal. O direito real de uso contemplado pelo ordenamento civil consiste na fruição da utilidade da coisa, quando o exigirem as necessidades do usuário e de sua família.

${ }^{24}$ Esse instrumento não se confunde com o plano de manejo, definido na Lei $n^{\circ}$ 9.985/2000 em seu art. $2^{\circ}$, inciso XVII, como “documento técnico mediante o qual, com fundamento nos objetivos gerais de uma unidade conservação, se estabelece o seu zoneamento e as normas que devem presidir o uso da área e o manejo dos recursos naturais, inclusive a implantação das estruturas físicas necessárias à gestão da unidade". Recentemente, em 21 de dezembro de 2017, o ICMBio, ouvindo as entidades representativas das populações extrativistas tradicionais, editou a Instrução Normativa $n^{\circ}$ 07/2017, que estabelece as diretrizes e procedimentos para elaboração e revisão dos planos de manejo nas unidades de conservação federais. Esta Instrução Normativa, ao reservar um Capítulo para as unidades de uso sustentável com população tradicional, estabeleceu, em seu art. 11, III, entre outros princípios e diretrizes, a "garantia dos meios necessários e adequados para a efetiva participação das populações tradicionais nos processos decisórios e de seu protagonismo no planejamento e gestão das RESEX e RDS [...]”.
} 
8,5 milhões de hectares e beneficiando mais de 50 mil pessoas" ${ }^{26}$ Após esse período, a disciplina estabelecida pelo referido decreto sofreu significativa modificação por causa da entrada em vigor da Lei $\mathrm{n}^{\circ}$ 9.985/2000, que instituiu o Sistema Nacional de Unidades de Conservação da Natureza - SNUC, ainda que disposições que não a contrariam tenham permanecido em vigência.

A partir da Lei do SNUC as Reservas Extrativistas passaram a fazer parte desse sistema, na condição de Unidades de Conservação de Uso Sustentável (art. 14, IV). Essas unidades, diferentemente das denominadas Unidades de Proteção Integral, não têm como objetivo básico apenas a preservação da natureza, mas sim a sua compatibilização com o uso sustentável de recursos naturais (art. $7^{\circ}, \S 2^{\circ}$, Lei do SNUC). No caso específico das Reservas Extrativistas, esse objetivo é, inclusive, precedido de outro: "a proteção dos meios de vida e da cultura das populações extrativistas tradicionais" (art. 18, Lei do SNUC). O reconhecimento desse elemento, antecedido da definição das Reservas Extrativistas como "área utilizada por populações extrativistas tradicionais, cuja subsistência baseia-se no extrativismo" (art. 18, Lei do SNUC), representa importante complemento aos termos do conceito estabelecido pelo art. $1^{\circ}$, Decreto ${ }^{\circ}$ 98.897/1990.

Além disso, a Lei do SNUC também manteve a figura do contrato de concessão de direito real de uso: o art. $18, \S 1^{\circ}$, dispõe que a área das Reservas
Extrativistas é de domínio público, cujo uso é concedido às populações extrativistas tradicionais na forma do art. 23 e da regulamentação específica (in casu, o Decreto no 98.897/1990). O art. 23, § 2º III, Lei do SNUC por sua vez, tal como o Decreto $n^{\circ}$ 98.897/1990, indica o contrato que regula a posse e o uso da área pela população extrativista tradicional como sendo o contrato de concessão de direito real de uso.

Outra permanência no regime da Lei do SNUC em relação ao Decreto $n^{\circ} 98.897 / 1990$ diz respeito a algumas disposições do Decreto $\mathrm{n}^{\circ} 4.340 / 2002$ que regulamentou diversos dispositivos da Lei do SNUC, trazendo disciplina específica quanto à criação de Unidades de Conservação, à elaboração do Plano de Manejo e ao funcionamento do Conselho Deliberativo das Reservas Extrativistas.

Nesse sentido, o art. $2^{\circ}$, Decreto $n^{\circ} 4.340 / 2002$, promove uma modificação apenas parcial em relação aos requisitos estabelecidos pelo art. $3^{\circ}$, Decreto $n^{0} 98.897 / 1990$, ao estabelecer que o ato de criação de uma Reserva Extrativista deve indicar:

I - a denominação, a categoria de manejo, os objetivos, os limites, a área da unidade e o órgão responsável por sua administração;

II - a população tradicional beneficiária, no caso das Reservas Extrativistas e das Reservas de Desenvolvimento Sustentável;

[...]

IV - as atividades econômicas, de segurança e de defesa nacional envolvidas.

\footnotetext{
25 A primeira Reserva de Desenvolvimento Sustentável criada no direito brasileiro foi a Reserva de Desenvolvimento Sustentável Mamirauá. A figura foi posteriormente incorporada à Lei do SNUC, que a define como "[...] uma área natural que abriga populações tradicionais, cuja existência baseia-se em sistemas sustentáveis de exploração dos recursos naturais, desenvolvidos ao longo de gerações e adaptados às condições ecológicas locais e que desempenham um papel fundamental na proteção da natureza e na manutenção da diversidade biológica" (art. 20, caput). Sobre o tema, ver Queiroz, H. L. A reserva de desenvolvimento sustentável Mamirauá. Estudos Avançados, São Paulo, v. 19, n. 54, p. 183-203, ago. 2005. Disponível em: $<$ http://www.scielo.br/scielo.php?script=sci_arttext\&pid=S0103-40142005000200011\&lng=en\&nrm=iso $>$. Acesso em 16 set. 2018.

${ }^{26}$ Soerguimento tecnológico e econômico do extrativismo na Amazônia. Brasília: CGEE, 2011. Disponível em:https://www.cgee.org.br/documents/10195/734063/livro_extrativismo_capa_01092011_7461.pdf/a7dc12a5-3dcd-4dcb-994e-92478ba4a6c7?version=1.4. Acesso em 16. set. 2018.
} 
De fato, é possível notar que o art. $2^{\circ}$, II, Decreto $\mathrm{n}^{\circ} 4.340 / 2002$, corresponde ao requisito da população destinatária e o art. $2^{\circ}, I V$, Decreto $n^{\circ}$ 4.340/2002, corresponde à indicação das medidas a serem tomadas pelo Poder Público - ambos previstos no art. $3^{\circ}$, Decreto $\mathrm{n}^{\circ}$ 98.897/1990.

$\mathrm{O}$ art. $2^{\circ}$, I, Decreto $n^{\circ} 4.340 / 2002$, encontra correspondência em parte com o requisito do limite geográfico (art. 3º Decreto n ${ }^{\circ}$ 98.897/1990) e com a indicação do IBAMA, sucedido pelo ICMBio por força da Lei ${ }^{\circ} 11.516 / 2007,{ }^{27}$ como órgão fiscalizador das Reservas Extrativistas (art. 5 ${ }^{\circ}$, Decreto $\mathrm{n}^{\circ}$ 98.897/1990). Os demais requisitos, como a denominação, a categoria de manejo e os objetivos estes já previstos na própria legislação - constituem meros acréscimos nominais à disciplina anterior.

Não obstante, destoa a previsão de indicação de órgão responsável pela administração da Unidade de Conservação. Essa modificação deve ser encartada em um conjunto de perdas significativas do arranjo jurídico das Reservas Extrativistas provocadas pela Lei do SNUC em decorrência de modificações em relação ao regime do Decreto $n^{\circ}$ 98.897/1990.

Essas perdas se concentram em modificações implantadas pela Lei do SNUC que (i) reduzem os poderes conferidos no contrato de concessão de direito real de uso às associações concessionárias; (ii) restringem as condições de efetivação de uma tutela ampla sobre os meios de vida e a cultura das populações extrativistas; e (iii) instituem a obrigatoriedade de um plano de manejo cuja responsabilidade pela elaboração e aprovação fica a cargo do órgão gestor.

Quanto ao primeiro aspecto, descaracterizando a figura do contrato de concessão de direito real de uso, a Lei do SNUC estabelece, em seu art. 18, § $2^{\circ}$, que a gestão da Reserva Extrativista "será gerida por um Conselho Deliberativo, presidido pelo órgão responsável por sua administração e constituído por representantes de órgãos públicos, de organizações da sociedade civil e das populações tradicionais residentes na área [...]". Com isso, a Lei do SNUC quebrou a arquitetura básica instituída pelo Decreto $\mathrm{n}^{\circ} 98.897 / 1990$, que delegava a gestão e a administração da Reserva à associação (concessionária do direito real de uso), cabendo ao Poder Público (concedente) apenas o controle e a fiscalização sobre o uso da área.

A nova arquitetura, um tanto confusa, ainda que mantenha a previsão do contrato de concessão de uso celebrado com a associação concessionária, confere expressamente a gestão da área a um Conselho Deliberativo (art. 18, § $2^{\circ}$, Lei do SNUC), responsável pela aprovação do Plano de Manejo (art. $18, \S 5^{\circ}$, Lei do SNUC), que será presidido por um chefe de unidade (art. 17, Decreto $\mathrm{n}^{\circ} 4.340 / 2002$ ). O chefe da unidade, como se pode deduzir do art. 18, $\S 2^{\circ}$, Lei do SNUC, é preposto do órgão responsá-

\footnotetext{
${ }^{27}$ Segundo a redação original do art. $6^{\circ}$, Lei n ${ }^{\circ}$ 9.985/2000 (Lei do SNUC), o SNUC seria gerido pelo Conselho Nacional do Meio Ambiente (CONAMA) na condição de órgão consultivo e deliberativo com a atribuição de acompanhar a implementação do Sistema, pelo Ministério do Meio Ambiente (MMA), na condição de órgão central com a finalidade de coordená-lo, e pelo IBAMA, na condição de órgão executor, "com a função de implementar o SNUC, subsidiar as propostas de criação e administrar as unidades de conservação federais, estaduais e municipais, nas respectivas esferas de atuação". Com a criação do Instituto Chico Mendes de Conservação da Biodiversidade (ICMBio) pela Lei n 11.516/2007, as competências originariamente atribuídas ao IBAMA foram transferidas ao novo órgão. Assim, conforme o art. $1^{\circ}$, II, Lei $\mathrm{n}^{\circ} 11.516 / 2007$, o ICMBio é autarquia federal vinculada ao MMA com a finalidade de "executar as políticas relativas ao uso sustentável dos recursos naturais renováveis e ao apoio ao extrativismo e às populações tradicionais nas unidades de conservação de uso sustentável instituídas pela União". Ainda, na forma do art. $6^{\circ}$, III, Lei n ${ }^{\circ} 9.985 / 2000$ (Lei do SNUC), o ICMBio passou à condição de órgão executor no SNUC, função que deve ser exercida pelo IBAMA apenas em caráter supletivo.
} 
vel pela administração da Reserva Extrativista - o ICMBio (art. $6^{\circ}$, III, Lei do SNUC).

Assim, observando os exatos termos da Lei do SNUC e do Decreto que a regulamenta, a área das Reservas Extrativistas é:

- Concedida à população extrativista tradicional (art 18, § $1^{\circ}$ );

- Gerida pelo Conselho Deliberativo (presidido pelo ICMBio e composto por representantes de órgãos públicos, de organizações da sociedade civil e das populações tradicionais residentes - art. 18, $\S 2^{\circ}$ );

- Administrada pelo ICMBio (art. 18, $\S 4^{\circ}$ ); e

- Chefiada pelo "chefe da unidade de conservação" (servidor designado pelo ICMBio, conforme art. 17, Decreto 4.340/2002).

Não é preciso muito para justificar a conflitualidade decorrente de um modelo de gestão desse modo fracionado, que desnatura completamente o vínculo estabelecido entre o Poder Público e a associação da população extrativista tradicional pelo contrato de concessão de direito real de uso. Essa distorção fica clara quando se nota que o Conselho Deliberativo da Reserva Extrativista tem, na população concessionária, apenas um entre os diversos representantes indicados no art. 17, $\S \S 1^{\circ}$ e $2^{\circ}$, Decreto $n^{\circ} 4.340 / 2002$, e não, como deveria ser, o principal deles. Isso também se evidencia pelo fato de que (i) o Plano de Manejo da Reserva Extrativista, que regula todas as atividades da área, é aprovado pelo Conselho Deliberativo e pelo Poder Público, não pela concessionária (art. $18, \S 5^{\circ}$, Lei do SNUC):28 (ii) a realização de pesquisa na área objeto de concessão não se sujeita à concessionária, mas ao próprio poder concedente (art. $18, \S 4^{\circ}$, Lei do SNUC); e (iii) o contrato de concessão de direito real de uso e o termo de compromisso firmados entre Poder Público e populações tradicionais podem ser revistos para serem adaptados ao Plano de Manejo aprovado pelo Conselho Deliberativo (art. 13, Decreto $\mathrm{n}^{\circ} 4.340 / 2002$ ).

Quanto ao segundo aspecto, a Lei do SNUC, ao fixar como objetivos básicos das Reservas Extrativistas "proteger os meios de vida e a cultura dessas populações" e "assegurar o uso sustentável dos recursos naturais da unidade", estende o objeto de tutela jurídica estatal para alcançar as populações extrativistas tradicionais, em especial seus meios de vida e cultura, assegurando o uso dos recursos naturais por essas populações de modo sustentável. Aditando-se a isso a definição de Reserva Extrativista contida no primeiro período do caput do mesmo art. 18 como "área utilizada por populações extrativistas tradicionais", a interpretação do comando legal não suscita dúvida: as Reservas Extrativistas, distintamente de todas as demais Unidades de Conservação, voltam-se para a defesa de um especial tipo de uso sustentável de recursos naturais: o desenvolvido pela população extrativista tradicional.

Esse uso envolve, nos termos do Decreto ${ }^{\circ}$ 6.040/2007, a forma própria de organização social, de reprodução cultural, social, religiosa, ancestral e econômica (art. $3^{\circ}$, I). O mesmo diploma estabeleceu como objetivo principal da Política Nacional de Desenvolvimento Sustentável dos Povos e Comunidades Tradicionais (PNPCT) "o desenvolvimento sustentável dos Povos e Comunidades Tradicionais, com ênfase no reconhecimento, fortalecimento e garantia dos seus direitos territoriais, sociais, ambientais, econômicos e culturais, com respeito

\footnotetext{
${ }^{28}$ O processo de aprovação do Plano de Manejo das Reservas Extrativistas, atualmente, está estabelecido no art. $9^{\circ}$, Instrução Normativa $\mathrm{N}^{\circ}$
} 7/2017/GABIN/ICMBIO. 
e valorização à sua identidade, suas formas de organização e suas instituições" (art. $2^{\circ}$, Anexo, Decreto $n^{\circ}$ 6.040/2007).

Esse é o amplo campo sobre o qual deve recair a proteção legal, consubstanciada na expressão "meios de vida e cultura" da população extrativista tradicional. Ignorando esse inquestionável elastério, a lei acaba contemplando inúmeras distorções ao estabelecer diversas restrições quanto às atividades eventualmente realizadas pelas populações extrativistas tradicionais. Nesse sentido, a Lei do SNUC proíbe sem ponderações a "exploração de recursos minerais e a caça amadorística ou profissional" (art. 18, $6^{\circ}$ ); afirma que "a exploração comercial de recursos madeireiros só será admitida em bases sustentáveis e em situações especiais e complementares às demais atividades desenvolvidas na Reserva Extrativista, conforme o disposto em regulamento e no Plano de Manejo da unidade" (art. 18, § $7^{\circ}$ ); e, ainda, estabelece outras proibições relativas a usos e práticas (art. 23, $\S 2^{\circ}$ ). Por óbvio, essas restrições deveriam estar submetidas a um juízo de ponderação expresso, que considerasse o objetivo da Unidade de Conservação e, com ele, o próprio objeto da tutela jurídica estatal deferida para as Reservas Extrativistas.

Desprovidas dessa ponderação, essas proibições genéricas (aditadas por muitas outras em diversos diplomas normativos ${ }^{29}$ ) colocam em risco o modo de produção e reprodução de vida dessas populações, ampliando-se sua vulnerabilidade material e cultural, vilipendiando-se precisamente o bem tutelado pela ordem jurídica. Veja-se, por exemplo, que a proibição genérica da caça (art. $18, \S 6^{\circ}$, Lei do SNUC), sem excepcionar a caça de subsistência, poderia comprometer elementos estruturais historicamente cristalizados no modo de produção da vida material e cultural da população extrativista, com profundos reflexos nas rotinas, valores, representações culturais e religiosas sustentadas precisamente nessa atividade.

De outro lado, reafirmando a importância do extrativismo para a reforma agrária, foi editada em 2008 a Portaria Interministerial MDA/MMA $\mathrm{n}^{\circ} 03 / 2008$. Essa portaria, que sucedeu a Portaria Interministerial MDA/MMA n ${ }^{\circ} 13 / 2002$, manteve o reconhecimento, em seu art. $1^{\circ}$, dos "povos e comunidades tradicionais habitantes das Reservas Extrativistas, Reservas de Desenvolvimento Sustentável e Florestas Nacionais, como potenciais beneficiários do Programa Nacional de Reforma Agrária - PNRA". A partir disso, o art. $1^{\circ}, \S 2^{\circ}$, Portaria Interministerial MDA/MMA n ${ }^{\circ} 03 / 2008$, também os considerou como potenciais beneficiários do Programa Nacional de Fortalecimento da Agricultura Familiar (PRONAF). Essas disposições são adequadas ao disposto no art. $3^{\circ}, \S 2^{\circ}$, III, Lei $\mathrm{n}^{\mathrm{o}} 11.326 / 2006$, que equipara os extrativistas aos agricultores familiares para fins da Política Nacional da Agricultura Familiar. ${ }^{30}$

\section{Necessidade de regulamentação específica}

Como se pode notar, a disciplina prevista pela Lei do SNUC e pelo Decreto ${ }^{\circ}$ 4.340/2002 deixa

\footnotetext{
${ }^{29}$ Por exemplo, a Lei n ${ }^{\circ} 5.197 / 1967$ que “dispõe sobre a proteção à fauna e dá outras providências”, previu em seu art. $1^{\circ}$ a proibição à caça de animais de quaisquer espécies, que vivam naturalmente fora do cativeiro; ou a Lei $\mathrm{n}^{\circ}$ 9.605/1998 que, ampliando a proibição da caça no direito brasileiro, estabeleceu que "caçar [...] espécimes da fauna silvestre [...] sem a devida permissão, licença ou autorização da autoridade competente, ou em desacordo com a obtida", constitui crime contra a fauna.
} 
espaço para uma regulamentação específica das Reservas Extrativistas. Afinal, conforme o art. 46, Decreto $n^{\circ} 4.340 / 2002$, "cada categoria de unidade de conservação integrante do SNUC será objeto de regulamento específico". Ainda, segundo o parágrafo único do mesmo dispositivo, a competência para propor tal regulamentação é do MMA.

Essa previsão, que reforça a importância de regulamento específico para as unidades de conservação, ainda não foi atendida em relação às Reservas Extrativistas. Por esse motivo, no contexto atual, a disciplina dessas reservas se pauta por algumas regulamentações internas do próprio ICMBio. Contudo, como tais regulamentações estão deduzidas fundamentalmente em portarias e instruções normativas - que, embora relevantes, não possuem a mesma hierarquia de uma lei ou decreto -, permanece vigente como diploma específico o Decreto $n^{\circ} 98.897 / 1990$, obviamente naquilo que não tiver sido objeto de revogação pela Lei do SNUC e pelo Decreto ${ }^{\circ}$ 4.340/2002.

Assim, considerando que quase três décadas se passaram desde a edição do Decreto n ${ }^{\circ}$ 98.897/1990 e que, nesse período, as experiências com o instituto das Reservas Extrativistas permitiram vislumbrar acertos e pontos passíveis de adequação, um novo marco normativo se faz necessário para assegurar o contínuo desenvolvimento dessas reservas.
Com efeito, após a edição da Lei do SNUC, diversos movimentos no sentido de, novamente, regulamentar as Reservas Extrativistas por meio de um instrumento jurídico próprio, com o objetivo de dar novos contornos ao modelo, foram tentados sem êxito $^{31}$. Contudo, recentemente foi editada a Portaria Conjunta MMA/ICMBio n ${ }^{\circ}$ 96/2018, que criou a CONAREX - Comissão das Reservas Extrativistas Federais - que, conforme o art. $7^{\circ}$, “deverá em 120 dias, contados a partir da sua instalação, apresentar proposta de regulamentação dos dispositivos da Lei $\mathrm{n}^{\circ} 9.985$, de 18 de julho de 2000, referentes a Reservas Extrativistas".

Espera-se que nessa regulação, por meio da proposta de um novo decreto, seja possível ao menos mitigar os equívocos decorrentes da Lei do SNUC, tal como regulamentada pelo Decreto $\mathrm{n}^{\circ}$ 4.340/2002: que a nova disciplina (i) leve em conta que o objetivo básico da Reserva Extrativista, de proteção aos meios de vida e cultura das populações extrativistas tradicionais, que a distingue de todas as outras Unidades de Conservação, reclama um regime jurídico diferenciado; e que (ii) preserve a natureza, tanto quanto possível, do contrato de concessão de direito real de uso, que, por implicar a transferência de um direito real, deve qualificar e não desqualificar a condição de concessionária da população extrativista tradicional.

\footnotetext{
${ }^{30}$ Essa equiparação é condicionada à atenção, pelos extrativistas, aos seguintes requisitos, estabelecidos pela Lei $\mathrm{n}^{\circ}$ 11.326/2006: (i) exercer atividade extrativista de modo artesanal no meio rural, excluídos os garimpeiros e faiscadores (art. $3^{\circ}, \S 2^{\circ}$, II); (ii) utilizar "predominantemente mão-de-obra da própria família nas atividades econômicas do seu estabelecimento ou empreendimento (art. $3^{\circ}$, I); (iii) ter "percentual mínimo da renda familiar originada de atividades econômicas do seu estabelecimento ou empreendimento, na forma definida pelo Poder Executivo" (art. $3^{\circ}$, III); (iv) dirigir "seu estabelecimento ou empreendimento com sua família" (art. $3^{\circ}$, IV).

${ }^{31}$ No conjunto dessas tentativas encontram-se algumas que incluíam as Reservas de Desenvolvimento Sustentável. Sustenta-se, entretanto, que sejam distintas regulamentações para cada unidade de conservação sob o pressuposto de que não se trata apenas de categorias ambientais distintas, mas de categorias jurídicas distintas, com diversas percussões tanto do ponto de vista normativo, quanto empírico, apesar de haver identidade quanto à população.
} 
A intenção, ao se diferenciar a Reserva Extrativista das outras Unidades de Conservação e ao se prever a concessão de uso como instrumento contratual que disciplina a sua exploração sustentável, é fortalecer as reservas e a população que recebe o múnus público de administrá-la; não amesquinhá-la. ${ }^{32}$ Se a intenção fosse diversa, a lei reconheceria a prevalência do conhecimento técnico-burocrático-científico sobre o conhecimento extrativista tradicional na gestão sustentável de recursos naturais, o que não ocorre.

\section{Espaços públicos e competências: CONAREX P PLANAFE}

A Portaria Conjunta MMA/ICMBio $n^{\circ}$ 96/2018, que criou a CONAREX, decorre de um cuidadoso trabalho desenvolvido, ao longo do ano de 2017, por um Grupo de Trabalho (GT) ${ }^{33}$ constituído por servidores do MMA e do ICMBio e por lideranças comunitárias e assessores técnicos das populações extrativistas tradicionais, representadas pelo Conselho Nacional das Populações Extrativistas - CNS e pela Comissão Nacional para o Fortalecimento das Reservas Extrativistas e dos Povos Extrativistas Costeiros Marinhos - CONFREM.
Nos termos desse diploma, à CONAREX caberá "apoiar, propor e monitorar a execução de políticas relativas à proteção dos meios de vida e da cultura das populações extrativistas tradicionais, o uso sustentável dos recursos naturais renováveis das reservas extrativistas federais e a conservação da biodiversidade" (art. $1^{\circ}$ ), competindo-lhe, nos termos do art. $2^{\circ}$, atuar nos seguintes âmbitos, sem prejuízo de outros não indicados expressamente: criação de novas unidades; regularização fundiária; instrumentos de gestão, como plano de manejo, conselhos deliberativos e contratos de concessão de direito real de uso; capacitação de servidores que atuam junto às reservas extrativistas; biodiversidade; gestão de conflitos e violação de direitos; participação comunitária; políticas públicas que envolvam o extrativismo sustentável; captação de recursos e mobilização de parcerias para as organizações sociais concessionárias; produção agroextrativista e parcerias com órgãos de pesquisa e tecnologia. Em acréscimo a esse amplo campo de competência, ficou estabelecido o dever de redigir, em 120 dias, uma proposta de regulamentação dos dispositivos da Lei $n^{\circ}$ 9.985/2000, na forma de minuta de decreto.

O conjunto dessas competências será exercido por uma Comissão composta por quinze membros, sendo dois representantes do MMA, cinco

\footnotetext{
${ }^{32}$ Registre-se que esse entendimento encontra abrigo na Convenção 169 da OIT, ratificada pelo Decreto Legislativo $\mathrm{n}^{\circ} 143 / 2002$, que, em seu art. $2^{\circ}$, estabelece: "1.Os governos deverão assumir a responsabilidade de desenvolver, com a participação dos povos interessados, uma ação coordenada e sistemática com vistas a proteger os direitos desses povos e a garantir o respeito pela sua integridade. 2.Essa ação deverá incluir medidas: a) que assegurem aos membros desses povos o gozo, em condições de igualdade, dos direitos e oportunidades que a legislação nacional outorga aos demais membros da população; b) que promovam a plena efetividade dos direitos sociais, econômicos e culturais desses povos, respeitando a sua identidade social e cultural, os seus costumes e tradições, e as suas instituições; c) que ajudem os membros dos povos interessados a eliminar as diferenças sócio - econômicas que possam existir entre os membros indigenas e os demais membros da comunidade nacional, de maneira compatível com suas aspirações e formas de vida."

${ }^{33}$ O Grupo de Trabalho que, como resultado, apresentou a minuta da referida Portaria, constitui um exemplo emblemático da eficiência do protagonismo do movimento social na espacialidade pública estatal. Este GT foi instituído em 19 de maio de 2017 pela Portaria nº $187-$ MMA, depois de forte pressão de líderes e assessores técnicos junto ao então Ministro do Meio Ambiente, José Sarney Filho. Essa pressão culminou com a entrega oficial de uma minuta de portaria que instituía o referido GT, prontamente aceita pelo Ministro, sendo objeto de posteriores alterações.
} 
do ICMBio e oito representantes de organizações das populações extrativistas tradicionais (art. $3^{\circ}$ ). Em razão dessa composição expressar maioria não estatal, os servidores do Poder Público alteraram, sem o assentimento do GT, a minuta anteriormente aprovada para estabelecer que as decisões da Comissão devem ser tomadas por consenso (art. $3^{\circ}, \S$ $4^{\circ}$ ). Certamente tais servidores teriam agido melhor se modificassem a composição da Comissão, para fixar uma participação paritária entre representantes do Poder Público e da sociedade civil, uma vez que a imposição de consenso, por óbvio, poderá constituir um intransponível obstáculo para o exercício da referida competência. Evidentemente, esse dispositivo, implantado inadvertidamente na minuta aprovada pelo GT - não é demais reafirmar, sem o conhecimento e a aceitação das lideranças e assessores técnicos das entidades representativas da população tradicional - poderá comprometer a tão almejada regulamentação das Reservas Extrativistas nos 120 dias fixados pela referida Portaria.

Ao lado desse espaço público de participação voltado exclusivamente para as Reservas Extrativistas e sua população, foi instituído, pelo Decreto $\mathrm{n}^{\circ}$ 9.334/2018, o Plano Nacional de Fortalecimento das Comunidades Extrativistas e Ribeirinhas (PLANAFE), com a finalidade de "integrar e adequar as políticas públicas destinadas à melhoria da qualidade de vida e à conservação do meio ambiente e apoiar a Política Nacional de Desenvolvimento Sustentável dos Povos Tradicionais e Comunidades Tradicionais - PNPCT". ${ }^{34}$

Constituído de modo paritário entre Poder Público (sete representantes) e comunidade extrativista e ribeirinha (sete representantes), indicados pelo CNPT ${ }^{35}$, o Comitê Gestor do PLANAFE terá como competência realizar consultas sobre políticas, programas e ações governamentais (art. $4^{\circ}, \mathrm{I}$ ), propor a fixação de metas e orientar a formulação, a implementação, o monitoramento e a avaliação do PLANAFE (art. $4^{\circ}$, II) estruturado, neste diploma, em quatro eixos: inclusão social, fomento à produção sustentável, infraestrutura; gestão ambiental e territorial (art. $2^{\circ}$ ).

A importância da CONAREX e do PLANAFE reside no fato de constituírem um espaço estatal composto por representantes da sociedade civil diretamente afetados pelas ações governamentais objeto das competências da Comissão e do Plano Nacional. No caso das Reservas Extrativistas que, como se disse, tem sua finalidade como Unidade de Conservação centrada no especial modo de vida e cultura das populações tradicionais, a dialogicidade viabilizada em espaços dessa natureza assume

\footnotetext{
${ }^{34}$ A PNPCT foi instituída pelo Decreto ${ }^{\circ}$ 6.040/2007.

${ }^{35}$ Instituído pela Portaria IBAMA n ${ }^{\circ}$ 22-N/1992, o Centro Nacional de Desenvolvimento das Populações Tradicionais (CNPT) foi o primeiro espaço institucional na estrutura administrativa do Estado brasileiro destinado especificamente ao tratamento centralizado das questões pertinentes ao extrativismo. Concebido com uma estrutura altamente participativa, era constituído por entidades não-governamentais representativas das populações tradicionais, sendo sua presidência definida por eleição direta dos seus próprios membros. O CNPT teve sua atuação regulamentada através de um Regimento, aprovado pela Portaria IBAMA n ${ }^{\circ} 22-\mathrm{A} / 92$, que estabeleceu uma ampla competência (desenvolvimento sustentável com populações extrativistas; implantação, consolidação, gerenciamento e desenvolvimento das Reservas Extrativistas; promoção e incentivo ao estudo e ao desenvolvimento de tecnologias para as Reservas; promoção da comercialização e da industrialização de produtos gerados pelas populações tradicionais). Por força da Portaria ICMBio n ${ }^{\circ} 78 / 2009$, o órgão foi reestruturado, passando a se denominar Centro Nacional de Pesquisa e Conservação da Socio-biodiversidade Associada a Povos e Comunidades Tradicionais, mas mantendo a sigla "CNPT". Essa reestruturação alterou o foco do CNPT para a pesquisa voltada ao extrativismo e populações tradicionais. Nesse sentido, o art. $1^{\circ}$, I, d, Portaria ICMBio n $78 / 2009$, atribui ao Centro o "objetivo de promover pesquisa científica em manejo e conservação de ambientes e territórios utilizados por povos e comunidades tradicionais, seus conhecimentos, modos de organização social, e formas de gestão dos recursos naturais, em apoio ao manejo das Unidades de Conservação federais".
} 
ainda maior importância por romper a distância entre saber técnico-burocrático e saber tradicional-extrativista, que tem gerado tantos equívocos tanto no âmbito teórico (normativo, hermenêutico e de formulação de políticas públicas) quanto no âmbito empírico (administração, gestão e fiscalização).

Em um contexto cuja espacialidade pública passa a ser constituída por unidades administrativas nas quais se torna possível um diálogo construtivo entre técnicos da burocracia estatal e representantes de segmentos da sociedade diretamente envolvidos com a política pública que se pretende formular e executar, não apenas se ampliam as possibilidades de adequação entre política governamental e demanda social, mas também, e sobretudo, a partir dessa adequação torna-se mais consistente a expectativa de se conformar a ação administrativa à finalidade legal e, portanto, ao interesse público de efetivamente proteger o extrativismo sustentável no Brasil.

\section{Considerações finais}

Como mencionado no início, teve-se como objetivo central abordar os principais diplomas legais que demarcam o dever tutelar do Estado em relação ao instituto das Reservas Extrativistas, indicando as mais recentes medidas que apontam para uma eventual transformação desse dever.

A exposição evidencia a relevância do estabelecimento de um marco regulatório que torne o objetivo de proteção dos meios de vida, da cultura das populações e do uso sustentável dos recursos naturais das Reservas Extrativistas, um dever para o Estado. Afinal, da criação do instituto com o Decreto $\mathrm{n}^{\circ} 98.897 / 1990$ até os dias atuais, passando pela consolidação legislativa da Lei do SNUC, o extrativismo tradicional sustentável tornou-se um bem jurídico tutelado a partir do seu reconhecimento como uma forma de conjugação indissolúvel de desenvolvimento e conservação, fruto do conhecimento dos povos e comunidades tradicionais.

Não obstante, os retrocessos decorrentes da legislação que instituiu o SNUC também deixam claro que muito ainda deve ser feito, também no âmbito legislativo, para a melhoria da qualidade de vida das populações e a proteção da cultura e do meio ambiente ligado às Reservas Extrativistas.

Por certo, o período de vigência do Decreto $n^{\circ} 98.897 / 1990$, da Lei do SNUC e do Decreto $n^{\circ}$ 4.340/2002, constitui valioso instrumental de análise da precisão, oportunidade e conveniência de seus termos. Com a edição da Portaria Conjunta MMA/ICMBio n ${ }^{\circ}$ 96/2018, que criou a CONAREX, cabe agora aos técnicos do setor público e privado, dialogicamente, junto com a população extrativista - principal protagonista da exploração sustentável de recursos naturais - o estabelecimento de novas diretrizes normativas que garantam efetividade e eficácia social às disposições normativas que regulam a matéria.

Afinal, é inteiramente legítima a expectativa da população extrativista tradicional em não apenas retomar a plenitude dos direitos e deveres que lhe foram conferidos pelo Decreto $n^{\circ} 98.897 / 1990$, como também de garantir, por meio de novo marco regulatório, a efetiva proteção dos seus meios de vida e de sua cultura, assegurando o uso sustentável dos recursos naturais da unidade. Uma legitimidade, frise-se, obtida após décadas de contínua, sofrida e aguerrida proteção à floresta, constitutivas, no dizer de Chico Mendes, de "uma herança que foi conquistada, que custou sangue, custou sacrifício e a gente tem que marchar, marchar firme". ${ }^{36}$ 


\section{Referências}

Allegretti, M. H. A construção social de políticas ambientais: Chico Mendes e o Movimento dos Seringueiros. Tese de Doutorado. Brasília, Universidade Brasília, 2002.

Gomes, M. E. A. C. e. Participação popular no controle ambiental. Revista de Informação Legislativa, 26, 104, 1989.

Gomes, M. E. A. C. e; Felippe, L. D. Tutela jurídica sobre as reservas extrativistas. In: ARNT, R. (Ed.). O destino da floresta: reservas extrativistas e desenvolvimento sustentável na Amazônia. Rio de Janeiro/Curitiba: Relume-Dumará \& Instituto de Estudos Amazônicos e Ambientais, 1994.

Meirelles, H. L. Direito Administrativo Brasileiro, $17^{\text {a }}$ ed. São Paulo, Malheiros Editores, 1990.

Mello, C. A. B. de. Legalidade - discricionariedade: seus limites e controle'. Revista de Direito Público, 86, 42-59, 1988.

Queiroz, H. L. A reserva de desenvolvimento sustentável Mamirauá. Estudos Avançados, 19, 54, 183-203, 2005. Disponível em: $<$ http://www.scielo.br/scielo.php?script=sci_arttext\&pid $=$ S0103 $=40142005000200011-\& \operatorname{lng}=$ en\&nrmiso $>$

Soerguimento tecnológico e econômico do extrativismo na Amazônia. Brasília: CGEE, 2011. Disponível em: https:// www.cgee.org.br/documents/10195/734063/livro_extrativismo_capa_01092011_7461.pdf/a7dc12a5-3dcd-4dcb-994e-92478ba-4a6c7?version=1.4. Acesso em 16. set. 2018.

Vianna, L. P.; Sales, R. R. de. Análises e diretrizes para consolidação da categoria reserva extrativista. Brasília: WWF-Brasil, 2008.

\footnotetext{
${ }^{36}$ Allegretti, M. H. A Construção Social de Políticas Ambientais: Chico Mendes e o Movimento dos Seringueiros. Tese de Doutorado. Brasília, Universidade Brasília, 2002, p. 350.
} 